\title{
Paper
}

\section{Sintering and Mechanical Properties of Fly-ash/NiCr Compacts Prepared by Spark Plasma Sintering}

\author{
Mamoru Daio ${ }^{\text {th }}$, Kazuhiro Hasezaki ${ }^{\text {th }}$, Mariko Hosogi ${ }^{\text {th }}$, and Ichiro Yoshioka ${ }^{\text {is } 2}$ \\ ${ }^{4}$ Department of Materials Science, Shimane University, 1060 Nishikawatsu, Matsue 690-8504, Japan. \\ $\$ 2$ The Chugoku Electric Power Co., Inc., 4-33 Komachi, Naka-Ku, Hiroshima 730-8701, Japan.
}

Received June 25, 2010

\section{SYNOPSIS}

Fly-ash/NiCr-alloy functionally graded materials (FGMs) plates were prepared by spark plasma sintering (SPS); the plates were $100 \mathrm{~mm}$ in diameter and layer thicknesses of $0.6 \mathrm{~mm}$ and $1 \mathrm{~mm}$. The plates consisted of stacked layers; the layers had volume ratio compositions of fly-ash/ $\mathrm{NiCr}=(100 / 0(\mathrm{~A}), 60 / 40$ (B), 40/60 (C), 60/40 (B), $100 / 0$ (A)). Two sorts of FGMs specimens with three layers prepared by machined from the FGMs plates with $\mathrm{A} / \mathrm{B} / \mathrm{C} / \mathrm{B} / \mathrm{A}$ five layers were investigated using a three-point flexural test. One sort of specimens had the normal stacking structure $\mathrm{A} / \mathrm{B} / \mathrm{C}$, and the other had the reverse structure $\mathrm{C} / \mathrm{B} / \mathrm{A}$, for the loading nose. After investigating the strengths of these two stacking structures, the fracture origins were observed at the surface of the extending $\mathrm{C}$ layer of the $\mathrm{A} / \mathrm{B} / \mathrm{C}$ structures, and of the $\mathrm{A}$ layer surface of the $\mathrm{C} / \mathrm{B} / \mathrm{A}$ structures. The deformation mechanism, average strength, and Weibull modulus were ductile, $12.0 \mathrm{MPa}$, and 5.5 , respectively, for the normal $\mathrm{A} / \mathrm{B} / \mathrm{C}$ structure, and brittle, $46.7 \mathrm{MPa}$, and 13.1 , respectively, for the $\mathrm{C} / \mathrm{B} / \mathrm{A}$ reverse structure. The different strengths of the two structures were explained on the basis of the strength of the extending surface layer, A or C, and the residual stress caused by the difference in thermal expansion coefficients of the stacking layers in the two structures. It was concluded that the fracture strengths of stacked FGMs materials were dominated by the stress field between the constituent layers and by the loading direction.

KEY WORDS

functionally graded materials, fly-ash, spark plasma sintering, residual stress, Weibull modulus

\section{Introduction}

The management of coal fly-ash produced by coal-fired thermal power stations is a major problem in many parts of the world, and the quantity produced is increasing every year. Coal fly-ash is now used in civil engineering for the production of cement, concrete, porous bricks, and artificial aggregates $^{1-5)}$, as well as in fertilizers ${ }^{6-8)}$. The practical uses of powdered fly-ash are limited; the powdered form therefore needs to be converted into bulk materials for advanced and effective uses can be found in various fields to realize its full value. A fly-ash compact, with a mechanical strength reported to be the same as that of glass, has been made by spark plasma sintering (SPS) ${ }^{9}$.

In the present study, to enhance its strength, the fly-ash compact was sintered into functionally graded material (FGMs) plates, using fly-ash powder and $\mathrm{NiCr}$-alloy as the source materials, by spark plasma sintering (SPS). Metallographic investigations and mechanical properties are reported. The FGMs plates were constructed from layers consisting of the two source materials; the mechanical properties of two different stacking structures were investigated and discussed on the basis of residual stresses.

\section{Experimental procedures}

\subsection{Source powders}

Fly-ash and $\mathrm{NiCr}$-alloy were used as the source powders for the preparation of the sintered compact materials. The chemical compositions of the source powders are given in Table 1. The fly-ash powder, which was produced at Misumi Power Station, Japan (The Chugoku Electric Power Co., Inc., Hiroshima, Japan) had an average particle size of $19 \mu \mathrm{m}$; it also contained about $2 \%$ carbon from unburned coal. The NiCr-based alloy powder (Fukuda Metal Foil \& Powder Co., Ltd, Kyoto, Japan) had an average particle size of $65 \mu \mathrm{m}$.

\subsection{Spark plasma sintering}

The source powders and their mixtures had fly-ash $/ \mathrm{NiCr}$ ratios of 100/0 (A), 60/40 (B), and 40/60 (C) ${ }^{10)}$. The powder sources were stacked layer by layer in a graphite die 100 $\mathrm{mm}$ in diameter. A mechanical pressure of $50 \mathrm{MPa}$ was 
applied to the graphite punches. Sintering was performed with a pulsed current in a vacuum $(10 \mathrm{~Pa})$ at $1000^{\circ} \mathrm{C}$ for $25 \mathrm{~min}$. The temperature was measured using a radiation pyrometer. The displacement of the upper electrode was used to monitor sintering progress. Five-layer $(\mathrm{A} / \mathrm{B} / \mathrm{C} / \mathrm{B} /$ A) stacked FGMs plates with layer thicknesses of $0.6 \mathrm{~mm}$ and $1 \mathrm{~mm}$ were prepared. Free surface cracks on the FGMs plates were inspected using a liquid penetrant ${ }^{10)}$.

\subsection{Three-point flexural test}

Specimens $(3.0 \mathrm{~mm} \times 4.0 \mathrm{~mm} \times 36 \mathrm{~mm})$ were machined from the sintered plates. The specimen strengths were measured using the three-point method described in ASTM $\mathrm{D} 790^{11)}$. The relationships between layer stacking and loading point are given in Table 2 and Fig. 1. Specimens (a) were machined into FGMs plates with layers of thickness $0.6 \mathrm{~mm}$. Specimens (a) were five-layer structures $(\mathrm{A} / \mathrm{B} / \mathrm{C} /$
B/A) with a fly-ash side (A) load point. Two sorts of specimens (b-1) and (b-2) were three-layer structures and were machined from FGMs plates with layers of thickness $1 \mathrm{~mm}$. Both two sorts of specimens (b-1) and (b-2) have the same stacking structures. One sort of specimens $(b-1)$ were three-layer structures $(\mathrm{A} / \mathrm{B} / \mathrm{C})$ with a fly-ash side (A) load point. The other sort of specimens (b-2) reversed specimens $(\mathrm{b}-1)$ which were three-layer structures $(\mathrm{C} / \mathrm{B} /$ A) with a $\mathrm{NiCr}$ side (C) load point. The number of specimens (a), (b-1), and (b-2) were 16,10 , and 14 , respectively.

Three-point flexural tests were carried out using a SHIMADZU AG-100 kNG (Shimadzu, Kyoto, Japan), according to the procedure described in ASTM D 790 ${ }^{11}$, using the loading point sides shown in Table 2 and Fig. 1. The fracture surfaces of specimens $(b-1)$ and $(b-2)$ were

Table 1 Chemical compositions of coal fly-ash and of NiCr-based alloy.

\begin{tabular}{cccccccccc}
\hline \multirow{2}{*}{ Fly-ash } & Composition & $\mathrm{SiO}_{2}$ & $\mathrm{Al}_{2} \mathrm{O}_{3}$ & $\mathrm{Fe}_{2} \mathrm{O}_{3}$ & $\mathrm{~K}_{2} \mathrm{O}$ & $\mathrm{CaO}$ & $\mathrm{MgO}$ & $\mathrm{Na}_{2} \mathrm{O}$ & $\mathrm{C}$ \\
& wt. \% & 63 & 22 & 4 & 1 & 2 & 1 & 1 & 2 \\
\hline \multirow{2}{*}{$\mathrm{NiCr}$} & Composition & $\mathrm{Ni}$ & $\mathrm{Cr}$ & $\mathrm{Si}$ & $\mathrm{Mn}$ & & & & \\
& wt. \% & 78 & 20 & 1 & 1 & & & & \\
\hline
\end{tabular}

Table 2 Stacked layer specimens.

\begin{tabular}{|c|c|c|c|c|c|c|c|}
\hline $\begin{array}{c}\text { Specimen } \\
\text { No. }\end{array}$ & Volume fraction & 1 & 2 & 3 & 4 & 5 & $\begin{array}{l}\text { Load point } \\
\text { side }\end{array}$ \\
\hline (a) & Fly-ash/NiCr & $100 / 0$ & $60 / 40$ & $40 / 60$ & $60 / 40$ & $100 / 0$ & Fly-ash \\
\hline$(b-1)$ & Fly-ash/NiCr & $100 / 0$ & $60 / 40$ & $40 / 60$ & & & Fly-ash \\
\hline (b-2) & Fly-ash/NiCr & $40 / 60$ & $60 / 40$ & $100 / 0$ & & & $\mathrm{NiCr}$ \\
\hline
\end{tabular}

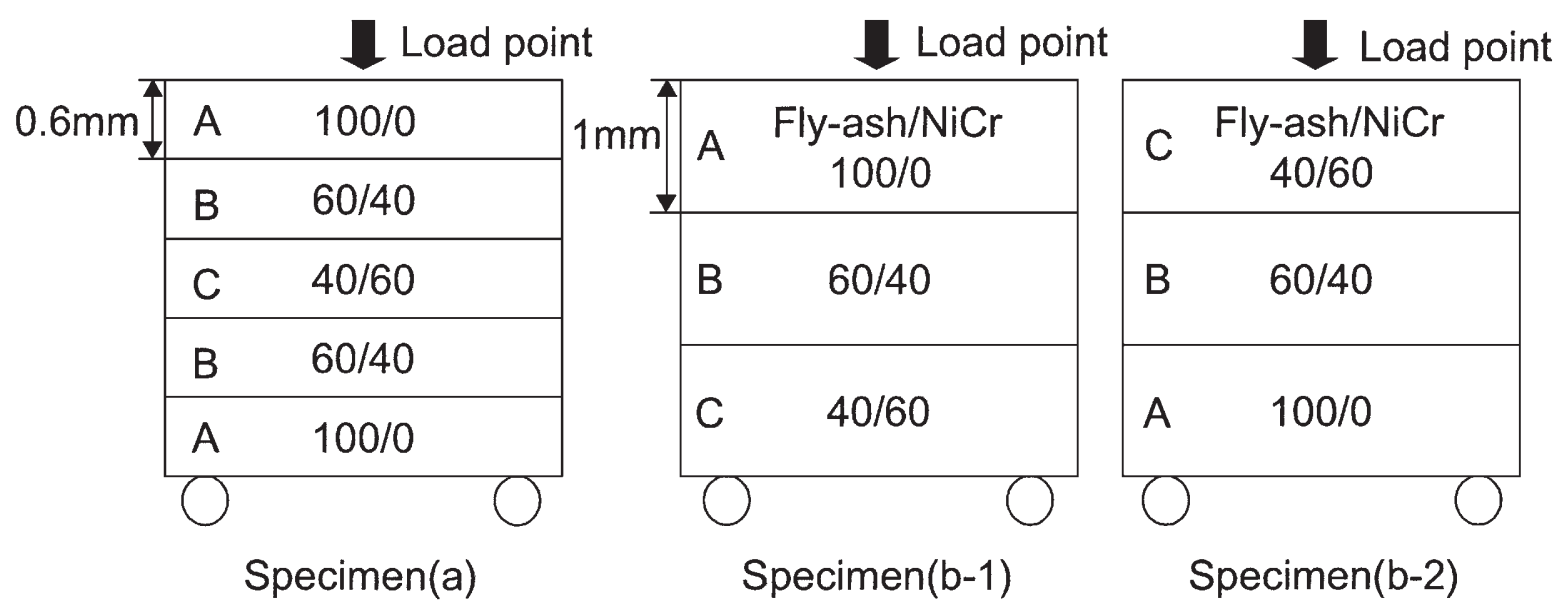

Fig.1 Stacked structures and loading point of specimens (a), (b-1), and (b-2). 
examined with an optical microscope to identify fracture origins and flaws.

Young's modulus was estimated from the linear relationship region in the load-displacement curve. The flexural strength $\sigma$ was evaluated using the Weibull distribution function ${ }^{12)}$ :

$$
P_{f}=1-\exp \left\{-\left(\frac{\sigma}{\sigma_{0}}\right)^{m}\right\}
$$

where $P_{f}$ is the fracture probability, $\sigma_{0}$ is the characteristic strength, and $m$ is the Weibull modulus. The Weibull modulus was calculated by the least-squares method from the linear relationship between mechanical load and the probability of failure. The Weibull modulus $m$ is a measure of the strength data scatter; the wider the distribution becomes, the smaller the value of $m$.

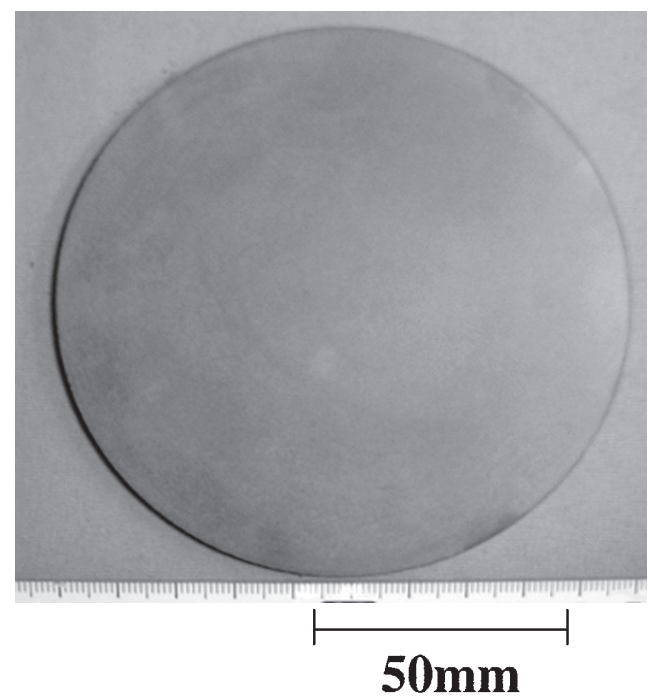

Fig.2 FGMs plate of stacked structure fly-ash $/ \mathrm{NiCr}=(100 / 0,60 /$ $40,40 / 60,60 / 40,100 / 0)$.

Fly-ash/NiCr

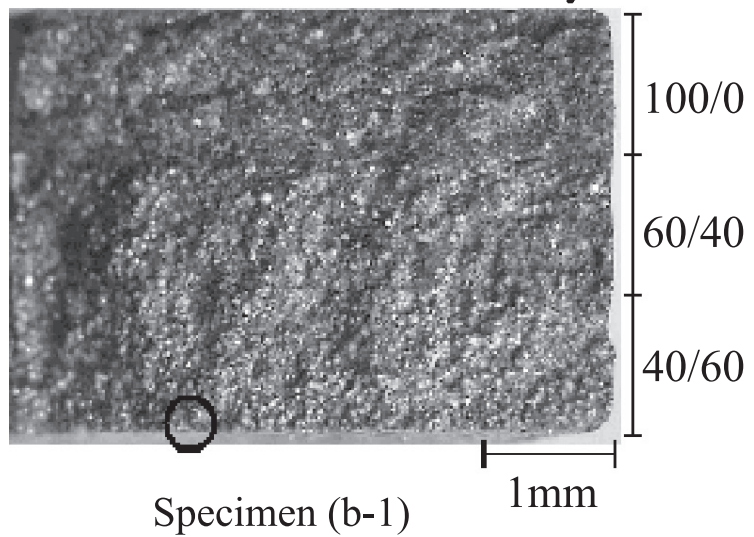

3 Results and discussion

Fig. 2 shows an FGMs plate of stacked structure A/B/C/ $\mathrm{B} / \mathrm{A}$. The presence of surface cracks on the FGMs plates was not observed using a liquid penetrant ${ }^{10)}$.

Fig. 3 shows the flexural stress-strain curves of specimens with two different stacking structures: normal, $\mathrm{A} / \mathrm{B} / \mathrm{C}$ (b-1), and reverse, C/B/A (b-2). The deformation character, Young's modulus $E$, and average flexural strength $\sigma$ of specimens (b-1) were ductile, $26.5 \mathrm{GPa}$, and 12.5 $\mathrm{MPa}$, respectively, and those of specimens (b-2) were brittle, $60.2 \mathrm{GPa}$, and $46.7 \mathrm{MPa}$, respectively. It was noted that the deformation character, $E$, and $\sigma$ had different loading directions, despite the layer structures being the same.

Optical micrographs of the fracture surfaces of specimens (b-1) and (b-2) in the three-point flexural test are shown in Fig. 4. Specimens (b-1) and (b-2) were found to be densely sintered. All specimens of fracture were found to have occurred at the extending bottom surface on

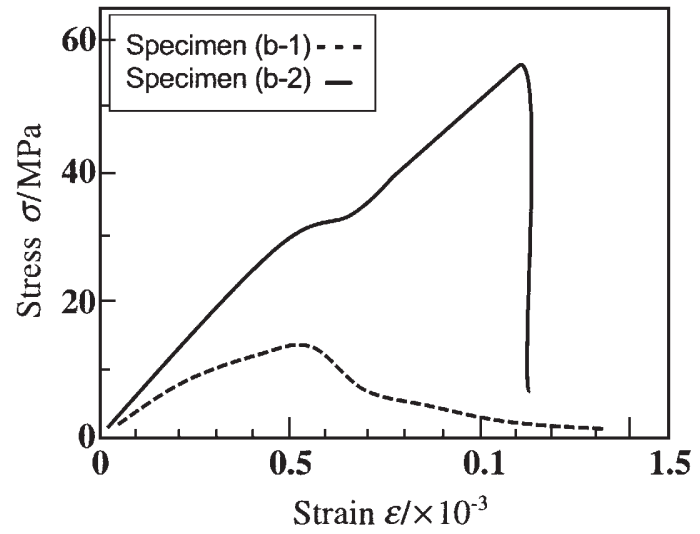

Fig.3 Stress-strain curves of specimens (b-1) and (b-2).

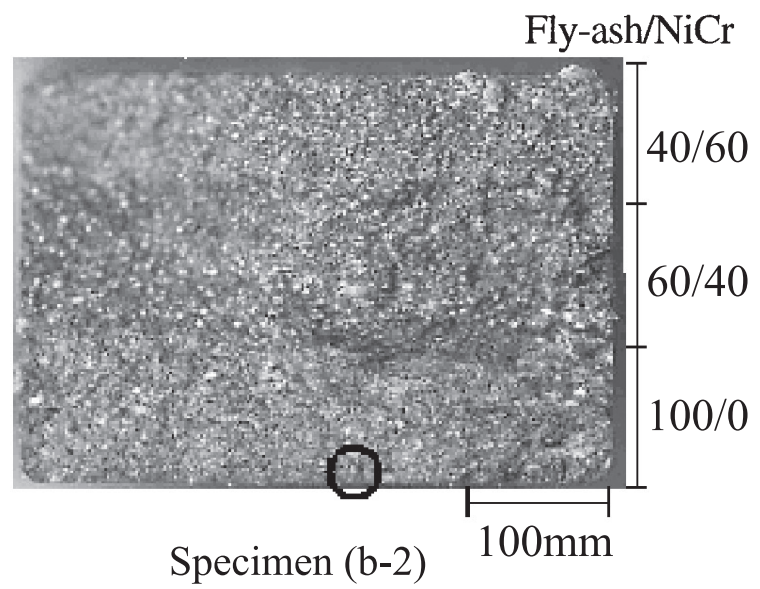

Fig.4 Fracture surfaces of specimens (b-1) and (b-2). 
the opposite side of the loading nose and not at the interfaces between the FGMs layers. These results indicate that the tensile stress loaded flexural test had worked on the extending surface of the specimens, and that the mechanical strength was dominated by the bottom layer of material.

Fig. 5 shows Weibull plots for all of the three-point flexural test data. The average flexural strength $\sigma$ and the Weibull modulus $m$ of specimens (a) were estimated to be 23.2 MPa and 4.5, respectively. These values were almost the same as that of monolithic fly-ash sintered compacts" ${ }^{9)}$. The Weibull modulus $m$ of specimens (b-1) was 5.5 , and that of specimens (b-2) was 13.1. The three-point flexural test results for specimens (a), (b-1), and (b-2) are given in Table 3. The differences between specimens (b-1) and (b-2) were explained by the different loading directions and by the residual stresses caused by the different thermal expansion coefficients of each stacking structure. The voids were observed to monolithic fly-ash sintered compacts. The voids squashed by the compression stress because the compression stress occurred in A layer (flyash $/ \mathrm{NiCr}=100 / 0$ ) which was tensile side as for specimens

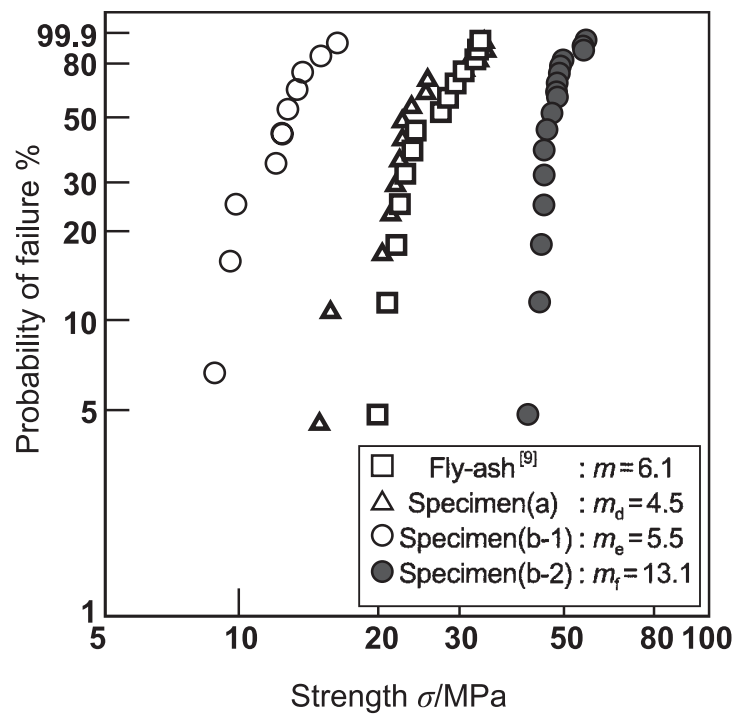

Fig.5 Weibull plots from three-point flexural tests. (b-2). Therefore the A layer was in a uniform situation, and it is thought that Weibull modulus increased. The basic factors that control the strength of ceramic materials will determine the flaw size generated during abrasive machining. Machining of ceramic materials showed that the micro cracks are often present in the machined ceramic components, and the subsurface damage and strength loss in machining ${ }^{13-15)}$. It was considered that the micro crack healing process depends strongly on its residual compression stress. The Weibull modulus increased due to surface smoothed by residual compression stress reported in elsewhere ${ }^{15)}$.

Fig. 6 suggests the situation of the residual stress in the specimens when the FGMs plates were machined into specimens (b-1) and (b-2). The strength and the Weibull modulus of specimens (a) were almost the same as that of monolithic fly-ash sintered compacts. It was considered that the situation of the residual stress of the A layer surface was the same as that of monolithic fly-ash sintered compacts. The residual compression stress in the FGMs plates was balanced by stress relief as the surface stress of the FGMs plates was relieved. The residual stresses in specimens (b-1) (A/B/C) and (b-2) (C/B/A) were caused by the machining of the FGMs plates; the A layer (flyash $/ \mathrm{NiCr}=100 / 0$ ) side experienced compression stress, and the $\mathrm{C}$ layer (fly-ash/ $\mathrm{NiCr}=40 / 60)$ side experienced tensile stress. The difference in strengths of the specimens was a result of the sum of the tensile stresses. It was noted that both the tensile stress direction due to the flexural loading nose and the residual tensile stress in the bottom layer (A) surface in the test nose $A / B / C(b-1)$ reduced the flexural strength. On the other hand, the tensile stress direction due to the flexural loading nose and the residual compression stress in the bottom layer $(\mathrm{C})$ surface in the test nose $\mathrm{C} / \mathrm{B} / \mathrm{A}(\mathrm{b}-2)$ increased the flexural strength and Weibull modulus. It was concluded that the fracture strengths of stacked FGMs materials were dominated by the stress field between the constituent layers and by the loading direction.

Table 3 Three-point flexural test results.

\begin{tabular}{ccccc}
\hline \multirow{2}{*}{ Specimen } & $\begin{array}{c}\text { Average Young's } \\
\text { modulus } \boldsymbol{E}(\mathrm{GPa})\end{array}$ & $\begin{array}{c}\text { Average Three-point } \\
\text { flexural strength } \sigma(\mathrm{MPa})\end{array}$ & $\begin{array}{c}\text { Weibull modulus } \\
\boldsymbol{m}\end{array}$ & Deformation \\
\hline (a) & 30.0 & 23.2 & 4.5 & Brittle \\
(b-1) & 26.5 & 12.0 & 5.5 & Ductile \\
(b-2) & 60.2 & 46.4 & 13.1 & Brittle \\
\hline
\end{tabular}




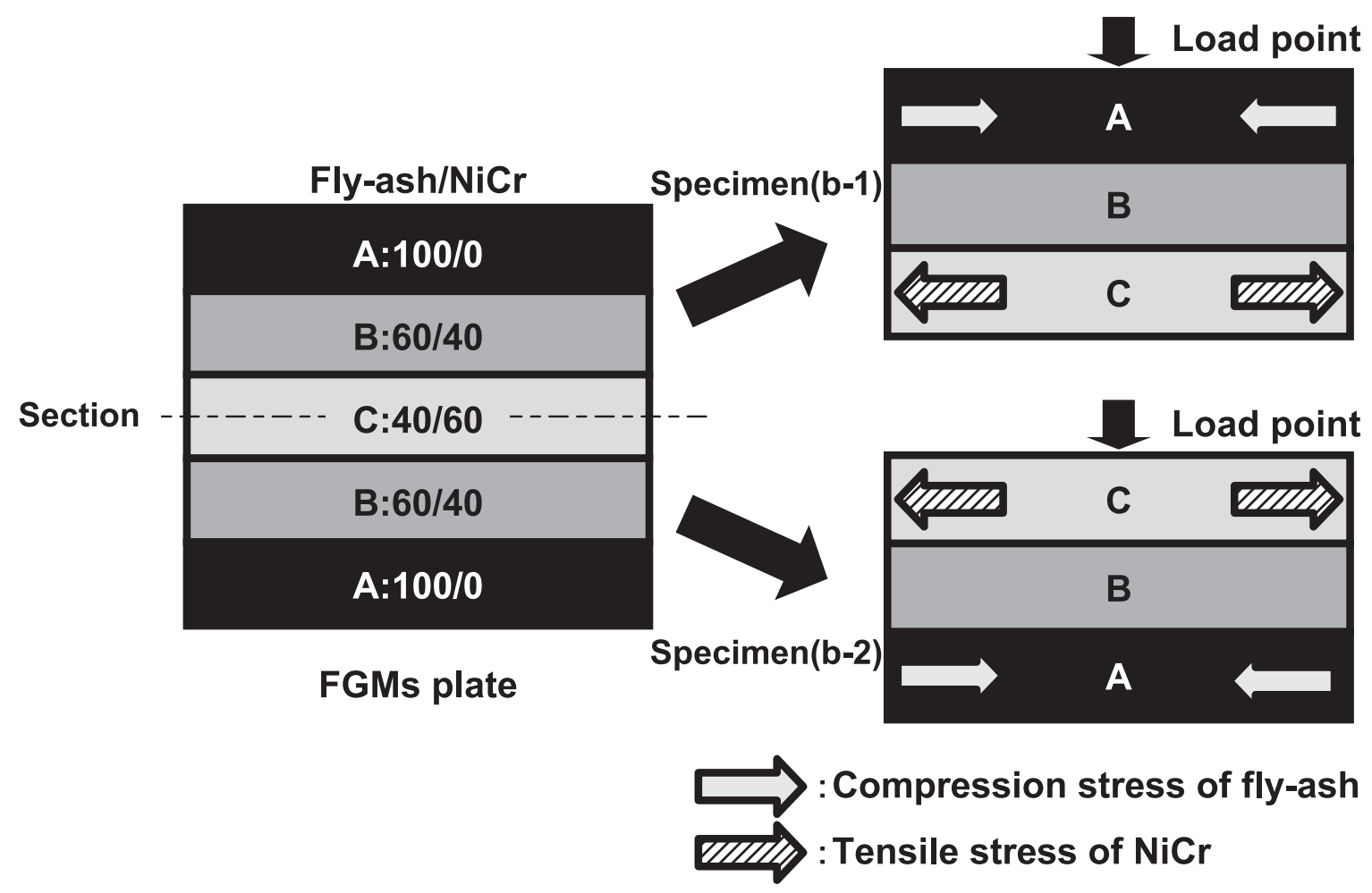

Fig.6 The situation of the residual stress in the specimens when the FGMs plates were machined into specimens (b-1) and (b-2).

\section{Conclusions}

The mechanical properties of FGMs plates prepared from fly-ash and $\mathrm{NiCr}$ by SPS were investigated to determine how to enhance the strength of the plates. The results were as follows:

(1) All specimens of fracture occurred at the bottom surface extended by the tensile stress loaded, but not at the interfaces between FGMs layers.

(2) The deformation, average strength, and Weibull modulus of stacked layers of composition (100/0, 60/ $40,40 / 60$ ), with load points on the $40 / 60$ layer, were brittle, $46.7 \mathrm{MPa}$, and 13.1 , respectively.

(3) The mechanical properties of a layer structure with volume ratios of fly-ash/NiCr $=(100 / 0,60 / 40,40 / 60$, $60 / 40,100 / 0$ ) were almost the same as those of monolithic fly-ash. On the other hand, the flexural strength and Weibull modulus of stacked layers of composition (100/0, 60/40, 40/60), with load points on the $40 / 60$ layer, were higher than those of monolithic fly-ash.

(4) The mechanical properties differed by load direction, despite the layer structures being the same. It was concluded that the fracture stress was dominated by a stress field of fracture origin.

\section{References}

1) S.H. Lee, H.J. Kim, E. Sakai, and M. Daimon: "Effect of particle size distribution of fly-ash-cement system on the fluidity of cement pastes", Cement and Concrete Research, 33(2003)763-768.

2) A. Oner, S. Akyuz, and R. Yildiz: "An experimental study on strength development of concrete containing fly-ash and optimum usage of fly-ash in concrete", Cement and Concrete Research, 35(2005)1165-1171.

3) C. Berryman, J. Zhu, W. Jensen, and M. Tadros: "Highpercentage replacement of cement with fly-ash for reinforced concrete pipe", Cement and Concrete Research, 35(2005) 1088-1091.

4) M.J. McCarthy and R.K. Dhir: "Development of high volume fly-ash cements for use in concrete construction", Fuel, 84(2005)1423-1432.

5) R.S. Iyer and J.A. Scott: "Power station fly-ash-a review of value-added utilization outside of the construction industry", Resources, Conservation and Recycling, 31 (2001)217-228.

6) M.R. Khan and M.W. Khan: "The effect of fly-ash on plant growth and yield of tomato", Environmental Pollution, 92(1996) 105-111.

7) S.K. Rautaray, B.C. Ghosh, and B.N. Mittra: "Effect 
of fly-ash, organic wastes and chemical fertilizers on yield, nutrient uptake, heavy metal content and residual fertility in a rice-mustard cropping sequence under acid lateritic soils", Bioresource Technology, 90(2003)275283.

8) L.P. Singh and Z.A.Siddiqui: "Effect of fly-ash and Helminthosporium oryzae on growth and yield of three cultivars of rice", Bioresource Technology, 86(2003) 73-78.

9) K. Hasezaki, A. Nakashita, G. Kaneko, and H. Kakuda: "Unburned carbon behavior in sintered coal fly-ash bulk material by spark plasma sintering", Materials Transactions, 48(2007)3062-3065.

10) M. Daio, K. Hasezaki, R. Shinoda, T. Oikawa, and I. Yoshioka: "Functionally Gradient Materials Plates using fly ash and $\mathrm{NiCr}$ prepared by Spark Plasma Sintering (SPS)", Journal of the Japan Society of
Powder Powder Metallurgy, 57(2010)333-337.

11) ASTM Standards D 790: "Standard test methods and reinforced plastics and electrical insulating materials".

12) W. Weibull: "A statistical theory of strength of materials", Royal Swedish Institute for engineering Research, (1939)1-45.

13) C.C. Liu: "Microstructural and reliability in grinding of silicon nitride", Materials Science and Engineering A, 379(2004)437-422.

14) T. Nishioka, Y. Tanaka, A. Yamakawa, and M. Miyake: "Relationship between Strength Degradation and Grain Depth of Cut during Grinding $\mathrm{Si}_{3} \mathrm{~N}_{4}$ ", Journal of the Ceramic Society of Japan, 103(1995)335-339.

15) W.H. Tuan and J.C. Kuo: "Effect of Abrasive Grinding on the Strength and Reliability of Alumina", Journal of the European Ceramic Society, 18(1998)799-806. 